\title{
Tert-butylhydroquinone attenuates the ethanol-induced apoptosis of and activates the Nrf2 antioxidant defense pathway in $\mathrm{H9c} 2$ cardiomyocytes
}

\author{
XIAOJING SHI, YANG LI, JUN HU and BO YU \\ Department of Cardiology, The First Affiliated Hospital of China Medical University, Shenyang, Liaoning 110001, P.R. China
}

Received November 13, 2015; Accepted May 13, 2016

DOI: $10.3892 / \mathrm{ijmm} .2016 .2605$

\begin{abstract}
Tert-butylhydroquinone (tBHQ), an inducer of nuclear factor erythroid 2-related factor $2(\mathrm{Nrf} 2)$, has been demonstrated to attenuate oxidative stress-induced injury and the apoptosis of human neural stem cells and other cell types. However, whether tBHQ is able to exert a protective effect against oxidative stress and the apoptosis of cardiomyocytes has not yet been determined. Thus, the objective of the present study was to determine whether tBHQ protects H9c2 cardiomyocytes against ethanol-induced apoptosis. For this purpose, four sets of experiments were performed under standard culture conditions as follows: i) untreated control cells; ii) cell treatment with $200 \mathrm{mM}$ ethanol; iii) cell treatment with $5 \mu \mathrm{M}$ tBHQ; and iv) cell pre-treatment with $5 \mu \mathrm{M}$ tBHQ for $24 \mathrm{~h}$, followed by medium change and co-culture with $200 \mathrm{mM}$ ethanol containing $5 \mu \mathrm{M}$ tBHQ for a further $24 \mathrm{~h}$. The viability of the cardiomyocytes was evaluated by 3-(4,5-dimethylthiazol-2-yl)-2,5-diphenyltetrazolium bromide (MTT) assay. The levels of intracellular reactive oxygen species (ROS) and apoptosis were assessed by flow cytometry. Protein expression was measured by western blot analysis, and Nrf2 nuclear localization was observed by immunofluorescence. Exposure to ethanol led to a decrease in the protein expression of Nrf2 and its downstream antioxidant enzymes, accompanied by an increase in ROS generation and in the apoptosis of H9c2 cells. Pre-treatment with tBHQ significantly prevented the $\mathrm{H} 9 \mathrm{c} 2$ cells from undergoing ethanol-induced apoptosis. $\mathrm{tBHQ}$ also increased the expression of B-cell lymphoma-2 (Bcl-2), whereas Bcl-2-associated X protein (Bax) expression was decreased. tBHQ promoted Nrf2 nuclear localization and
\end{abstract}

Correspondence to: Dr Bo Yu, Department of Cardiology, The First Affiliated Hospital of China Medical University, 155th North of Nanjing Street, Shenyang, Liaoning 110001, P.R. China

E-mail: shixiaojing3000@163.com

Key words: tert-butylhydroquinone, cardioprotection, ethanol, nuclear factor erythroid 2-related factor 2, antioxidant, Bcl-2, Bax, caspase- 3 , oxidative stress, apoptosis increased the expression of Nrf2, superoxide dismutase (SOD), catalase (CAT) and heme oxygenase-1 (HO-1), and simultaneously inhibited the ethanol-induced overproduction of intracellular ROS. Therefore, tBHQ confers protection against the ethanol-induced apoptosis of and activates the Nrf2 antioxidant pathway in $\mathrm{H} 9 \mathrm{c} 2$ cardiomyocytes.

\section{Introduction}

Excessive alcohol consumption increases the risk of heart disease, which continues to be one of the major causes of mortality and morbidity in many countries. High doses of ethanol can induce or exacerbate a series of pathophysiological disorders, leading to cardiomyocyte apoptosis, myocardial fibrosis, cardiomyopathy and congestive heart failure, all associated with alcoholic cardiomyopathy (ACM) (1).

Several mechanisms are involved in mediating the adverse effects of ethanol, including the induction of oxidative stress and apoptotic cell death (1). There is abundant evidence indicating that ethanol promotes cellular apoptosis and this in turn causes the loss of cardiomyocytes (2-5). Myocyte loss or cell death may be an important mechanism of organ dysfunction and pathology. Several early studies on animal models of ACM and patients with ACM support a role for myocyte loss as an underlying mechanism of ethanol-induced cardiac dysfunction $(2,6,7)$. These observations collectively imply that high-dose ethanol can diminish the cardiomyocyte population by the induction of apoptosis, which appears to result in subsequent abnormalities.

Compelling evidence indicates that oxidative stress, excessive intracellular reactive oxygen species (ROS) production, exceeding the antioxidant capacity of cells, plays a critical role in ethanol-induced apoptosis (8-11). ROS generation has been observed in ethanol-exposed cultured cells, including cardiac cells (8-10), as well as in the pathologies of several other types of cardiovascular insults, such as ischemia-reperfusion injury and cardiomyopathies (12). Others have suggested that ethanol-induced excessive ROS generation and oxidative stress may result from several processes or mechanisms involving mitochondrial cytochrome p450, xanthine oxidase, and NADPH oxidase $(13,14)$. Once produced, ROS may not only cause oxidative damage to biomolecules, such as DNA, protein and lipids, but can also regulate the expression 
of genes related to growth and cell death $(15,16)$. Of note, a number of events typical of oxidative stress are observed in cardiomyocytes following exposure to ethanol, which include myocyte loss and disarray (2), as well as changes in intracellular organelles. In addition, studies have also revealed that not only antioxidants, such as vitamin $\mathrm{E}$ and vitamin $\mathrm{C}(9)$, but also antioxidant enzymes, including superoxide dismutase (SOD), catalase (CAT) and heme oxygenase-1 (HO-1), all can inhibit ethanol-induced oxidative stress and apoptosis $(5,14,17)$. Therefore, it is important to find effective antioxidants or means with which to improve myocardial cell oxidative stress states caused by ethanol.

Nuclear factor erythroid 2-related factor 2 (Nrf2), a member of the cap ' $n$ ' collar family of basic region-leucine zipper (bZIP) transcription factors, which is expressed in a variety of tissues, is considered as one of the major intracellular defense systems with which to combat oxidative stress $(18,19)$. Under basal conditions, Nrf2 is located mainly in the cytoplasm bound to the Kelch-like ECH-associated protein 1 (Keap1), an adaptor protein for the Cul3-dependent ubiquitination and degradation of Nrf2. When activated, Nrf2 stabilizes and translocates to the nucleus, leading to the induction of the expression of phase II detoxifying and antioxidant genes, such as SOD, HO-1 and CAT $(18,19)$. Nrf2 has been shown to provide protection against a number of oxidative stress-related cardiovascular diseases (19-22), and may be a target for the treatment of cardiomyocyte injury (23). Preliminary data from a recent review revealed that low doses $(5 \mathrm{mM}$ ethanol) of alcohol increased the expression of Nrf2 and its homolog Nrf1 to provide cardioprotection (24). Recently, studies have also evidenced that the upregulation of Nrf2 by inducers, such as 3H-1,2-dithiole-3-thione (D3T) or sulforaphane (SFN), significantly decrease the ethanol-induced ROS generation in and the apoptosis of cells $i$ the nervous system $(25,26)$. However, an inducer of Nrf2 successfully employed to prevent ACM has not yet been identified.

Tert-butylhydroquinone (tBHQ), a potent inducer of Nrf2, has received increasing attention due to its ability to activate many cytoprotective and detoxifying enzymes (27-31). Of note, tBHQ has been approved for human use as a synthetic food antioxidant to protect oils and fats from oxidative deterioration and rancidity (32). tBHQ can enhance Nrf2-mediated transcriptional activation depending on the increase of Nrf2 protein stability through the inhibition of the Keap1-mediated ubiquitination $(27,28)$. There is substantial evidence to support the finding that $\mathrm{tBHQ}$ can aid in protecting various cells and organs against oxidative insults through the activation of Nrf2 signaling (29-31). A recent study revealed that tBHQ prevented ethanol-induced apoptosis by the induction of the Nrf2driven antioxidant response in cranial neural crest cells (33). Nevertheless, to date, in spite of being a well-recognized and effective strategy for the protection of a variety of different cell types and organs under oxidative stress conditions, the cardioprotective effects of tBHQ have not been investigated, at least to the best of our knowledge.

This study aimed to examine the effects of tBHQ on ethanol-induced oxidative stress and the apoptosis of a cultured H9c2 cell line, a cloned heart muscle cell line originating from embryonic rat hearts that presents many cardiomyocyte phenotypes.

\section{Materials and methods}

\section{Reagents}

Cell culture and treatment. The H9c2 cells (from the Shanghai Institutes for Biological Sciences, Shanghai, China) were cultured in Dulbecco's modified Eagle's medium (DMEM) with $10 \%$ fetal bovine serum (FBS), penicillin $\mathrm{G}(100 \mathrm{U} / \mathrm{ml})$ and streptomycin $(100 \mathrm{mg} / \mathrm{ml})$ (Gibco-BRL, Grand Island, NY, USA). The cells were maintained in a tissue culture incubator at $37^{\circ} \mathrm{C}$ in a $5 \% \mathrm{CO}_{2}$ atmosphere. The medium was changed every 2-3 days, and the cells were subcultured when the cell population density reached $70-80 \%$ confluence. In order to determine the optimal concentrations of ethanol (EtOH; Beijing Chemical Reagent Co., Ltd., Beijing, China) and tBHQ, the cells were exposed to various concentrations of both agents [EtOH: 0,25, 50, 100, 200, 400 and $800 \mathrm{mM}$ for $24 \mathrm{~h}$; and tBHQ (Sigma Chemical Co., St. Louis, MO, USA): 0, 0.625, 1.25, 2.5, 5, 10 , 20,50 and $100 \mu \mathrm{M}$ for $48 \mathrm{~h}$ ]. Four sets of experiments were then performed under standard culture conditions: i) untreated control cells; ii) cell treatment with $200 \mathrm{mM}$ ethanol; iii) cell treatment with $5 \mu \mathrm{M}$ tBHQ; and iv) cell pre-treatment with $5 \mu \mathrm{M}$ tBHQ for $24 \mathrm{~h}$, followed by medium change and co-culture with $200 \mathrm{mM}$ ethanol containing $5 \mu \mathrm{M}$ tBHQ for a further $24 \mathrm{~h}$.

\section{3-(4,5-Dimethylthiazol-2-yl)-2,5-diphenyltetrazolium bromide} (MTT) assay. Cell viability was examined by MTT assay. The H9c2 cells were seeded on 96-well plates at a density of $1.5 \times 10^{4}$ cells/well and were maintained in regular growth medium for $24 \mathrm{~h}$. The cells were then subjected to the ethanol and tBHQ treatments, as described above. After the treatments, the H9c2 cells were incubated with $20 \mu$ l MTT solution $(5 \mathrm{mg} / \mathrm{ml}$ phosphate buffer; obtained from Sigma Chemical Co.) at $37^{\circ} \mathrm{C}$ for $4 \mathrm{~h}$, and the purple formazan crystals were then solubilized with $150 \mu$ l DMSO (Sigma Chemical Co.) at room temperature for $10 \mathrm{~min}$. The absorbance at $490 \mathrm{~nm}$ was measured using a microplate reader (Sunrise RC; Tecan Group, Ltd., Mannedorf, Switzerland), and cell viability was expressed as a percentage of the control culture value.

Detection of apoptosis using Annexin V-FITC/propidium iodide (PI). The apoptotic cells were detected by using Annexin V-FITC apoptosis detection kits (Nanjing KeyGen Biotech Co., Ltd., Nanjing, China). The cells were collected, washed twice with PBS, resuspended in binding buffer $(10 \mathrm{mM}$ HEPES/NaOH $\mathrm{pH} 7.4,140 \mathrm{mM} \mathrm{NaCl}$ and $2.5 \mathrm{mM} \mathrm{CaCl}$ ) and incubated with Annexin $\mathrm{V}$ at room temperature in the dark for $15 \mathrm{~min}$. The cells were then centrifuged, resuspended in binding buffer, and incubated with PI. Subsequently, binding buffer (500 $\mu \mathrm{l}$ ) was added, and the apoptotic cells were assessed using a flow cytometer (FACSCalibur; BD Biosciences, Franklin Lakes, NJ, USA).

Measurement of ROS production. ROS generation was measured using a 5(6)-carboxy-2',7'-dichlorofluorescein diacetate (cDCFH-DA) detection kit (Beyotime Biotechnology, Jiangsu, China). After harvest, the cells were washed with PBS and then incubated with $10 \mu \mathrm{M}$ of cDCFH-DA diluted in serum-free medium at $37^{\circ} \mathrm{C}$ for $30 \mathrm{~min}$. The fluorescence intensity was monitored for $30 \mathrm{~min}$ after excitation at $488 \mathrm{~nm}$ 

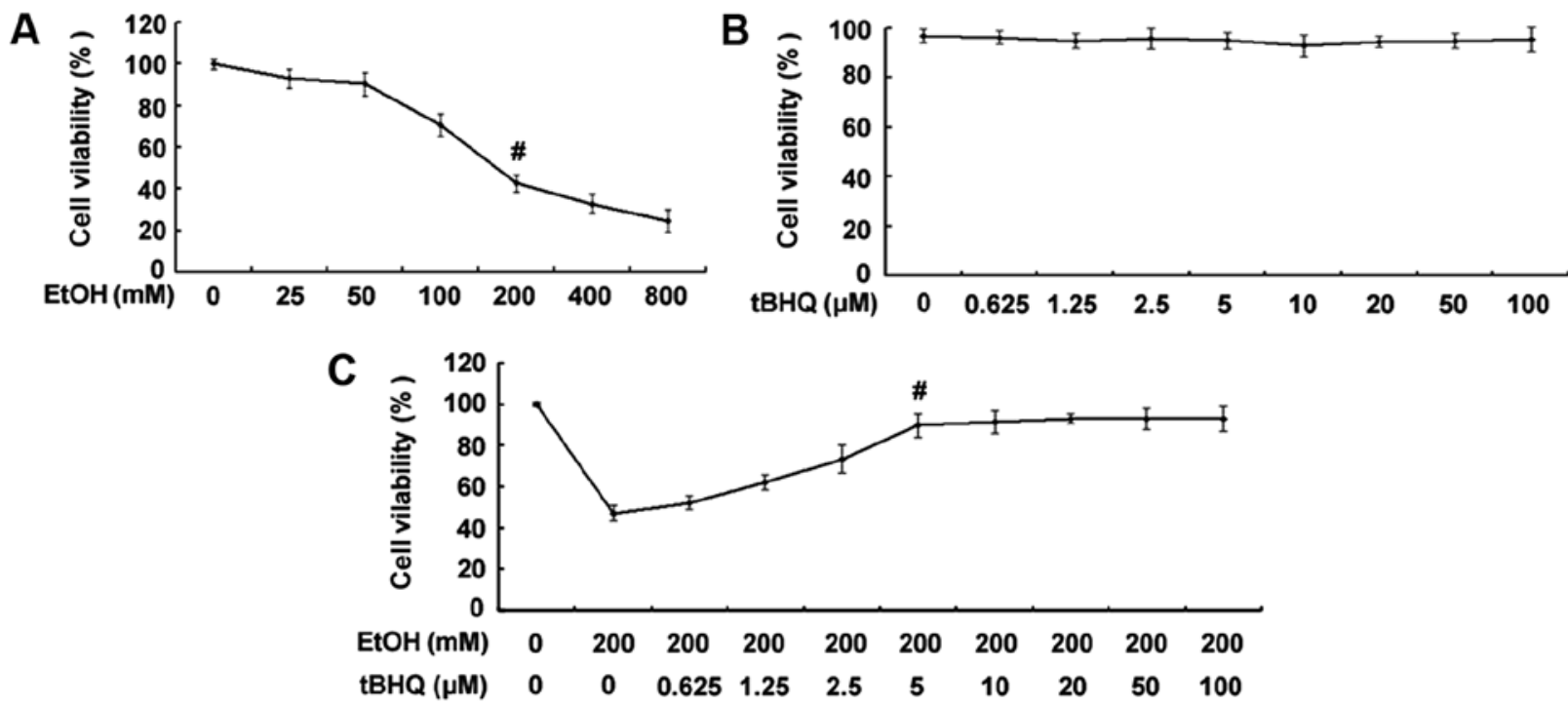

Figure 1. (A) Effect of various concentrations of ethanol (EtOH) on cell viability. $\mathrm{H} 9 \mathrm{c} 2$ cardiomyocytes were exposed to various concentrations of ethanol $(0$, $25,50,100,200,400$ and $800 \mathrm{mM}$ ) for $24 \mathrm{~h}$. Viable cells were identified by MTT assay. The data are shown as the means \pm SD; $\mathrm{n}=5$, ${ }^{\#} \mathrm{p}<0.01 \mathrm{vs}$. control group. (B) Effect of various concentrations of tert-butylhydroquinone (tBHQ) on cell viability. The H9c2 cardiomyocytes were incubated with various concentrations of tBHQ $(0,0.625,1.25,2.5,5,10,20,50$ and $100 \mu \mathrm{M})$ for $48 \mathrm{~h}$. Cell viability was measured by MTT assay. No decrease in the viability of cells exposed to various concentrations of tBHQ for $48 \mathrm{~h}$ was established. (C) tBHQ protects against EtOH-induced cell death of cultured H9c2 cardiomyocytes in a dose-dependent manner. The cells were treated with various concentrations of tBHQ $(0,0.625,1.25,2.5,5,10,20,50$ and $100 \mu \mathrm{M})$ for $24 \mathrm{~h}$, followed by incubation for $24 \mathrm{~h}$ with $200 \mathrm{mM}$ of ethanol. Cell viability was analyzed by MTT assay. The values are expressed as the means $\pm \mathrm{SD} ; \mathrm{n}=5$ experiments, ${ }^{\#} \mathrm{p}<0.05 \mathrm{vs}$. EtOH alone.

and emission at $525 \mathrm{~nm}$ using a FACSort cell sorter (BectonDickinson, San Diego, CA, USA).

Western blot analysis. The cells were lysed in ice-cold RIPA buffer [50 mM Tris ( $\mathrm{pH} 7.4), 150 \mathrm{mM} \mathrm{NaCl}, 1 \%$ Triton, $0.5 \%$ deoxycholate, $0.1 \%$ SDS, $1 \mathrm{mM}$ EDTA, $10 \mathrm{mM} \mathrm{NaF}$, and $0.1 \mathrm{mM}$ phenylmethylsulfonyl fluoride (PMSF)] to obtain total proteins. Nuclear protein was extracted using a nuclear and cytoplasmic protein extraction kit following the manufacturer's instructions. The protein concentration was detected via the BCA protein assay (Beyotime Biotechnology). Equal amounts of protein samples (50 $\mu \mathrm{g}$ protein/lane) were separated by 10-12\% sodium dodecyl sulfate-polyacrylamide gel electrophoresis (SDS-PAGE) and transferred onto polyvinylidene difluoride (PVDF) membranes. The non-specific antibodies were blocked with 5\% non-fat dried milk in PBS for $2 \mathrm{~h}$ at room temperature. Membranes were then incubated overnight at $4^{\circ} \mathrm{C}$ with primary antibodies directed against the Nrf2 (ab31163) at 1:200 dilution, and HO-1 (ab13248) (both from Abcam, Cambridge, UK), SOD (sc-101523) and CAT (A-4; sc-271358) (both from Santa Cruz Biotechnology, Inc., Santa Cruz, CA, USA), caspase-3 (3CSP03; ab2171; Abcam), Bcl-2-associated $\mathrm{X}$ protein (Bax; P-19; sc-526) and B-cell lymphoma-2 (Bcl-2; N-19; sc-492) (Santa Cruz Biotechnology, Inc.) at 1:500 dilution. The membranes were then washed with TBST 3 times and further incubated with horseradish peroxidase-conjugated secondary antibody $(1: 2,000)$ for $1 \mathrm{~h}$ at room temperature. After washing, the membranes were processed using an electrochemiluminescence (ECL) reagent (Pierce Biotechnology, Inc., Rockford, IL, USA) and the light emission was captured on $\mathrm{X}$-ray film. The signals were visualized by chemiluminescent horseradish peroxidase substrate and then subjected to a densitometric analysis and normalized to tubulin or lamin-B1.
Immunofluorescence staining. The cellular localization of Nrf2 was determined by immunofluorescence staining. The $\mathrm{H} 9 \mathrm{c} 2$ cells were seeded at $1.5 \times 10^{4}$ cells/well in glass chamber slides (glass coverslips) and cultured overnight at $37^{\circ} \mathrm{C}$. The cells were then exposed to ethanol or tBHQ alone, or in combination, as described above. At the end of incubation, the cells were washed twice in PBS and fixed in $4 \%$ paraformaldehyde for $10 \mathrm{~min}$ at room temperature. The cells were then permeabilized with $0.1 \%$ Triton X-100, washed and incubated with blocking buffer (10\% NGS) for $1 \mathrm{~h}$ at room temperature. The cells were then incubated overnight with primary antibodies against AC-tubulin (6-11B-1; ab24610) at 1:200 dilution and Nrf2 (both from Abcam) at a 1:200 dilution in a humidified chamber at $4^{\circ} \mathrm{C}$. Subsequently, the cells were washed with PBS and incubated with secondary antibodies conjugated to either FITC or TRITC at a dilution of 1:500 (Jackson ImmunoResearch Laboratories, Inc., West Grove, PA, USA) for $1 \mathrm{~h}$ at room temperature in the dark, and were then counterstained with DAPI dye to show the nuclear morphology. After the slides were rinsed with PBS, coverslips were mounted on slides, and images of the labeled cells were visualized and photographed using a confocal fluorescence microscope (TCS SP2; Leica, Wetzlar, Germany).

Statistical analysis. The data are presented as the means \pm SD. One-way analysis of variance (ANOVA) followed by the Student-Newman-Keuls test was applied to calculate the statistical significance between various groups. The differences were considered to be statistically significant at $\mathrm{p}<0.05$.

\section{Results}

Treatment with $\mathrm{tBHQ}$ markedly enhances the viability of $\mathrm{H} 9 \mathrm{c} 2$ cardiomyocytes exposed to ethanol. As shown in Fig. 1A, the 

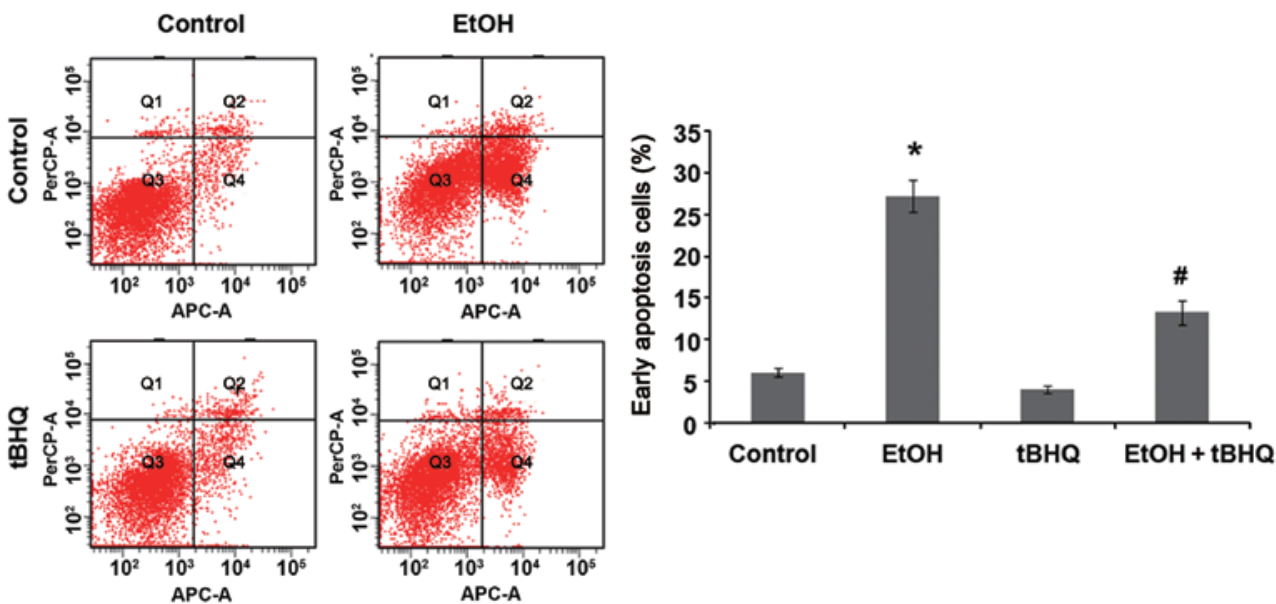

Figure 2. Flow cytometric analysis of the apoptotic of H9c2 cells with Annexin V-FITC indicated that pre-treatment with tert-butylhydroquinone (tBHQ) significantly prevented ethanol (EtOH)-induced apoptosis. Apoptosis was assessed in $\mathrm{H} 9 \mathrm{c} 2$ cells cultured in control medium (control), exposed to $200 \mathrm{mM}$ EtOH or $5 \mu \mathrm{M} \mathrm{tBHQ}(\mathrm{tBHQ})$ alone, or exposed to EtOH and pre-treated with tBHQ (EtOH $+\mathrm{tBHQ})$. The values are expressed as the means $\pm \mathrm{SD} ; \mathrm{n}=3$ experiments, p $<0.01$ vs. control, ${ }^{\#} \mathrm{p}<0.05$ vs. EtOH.
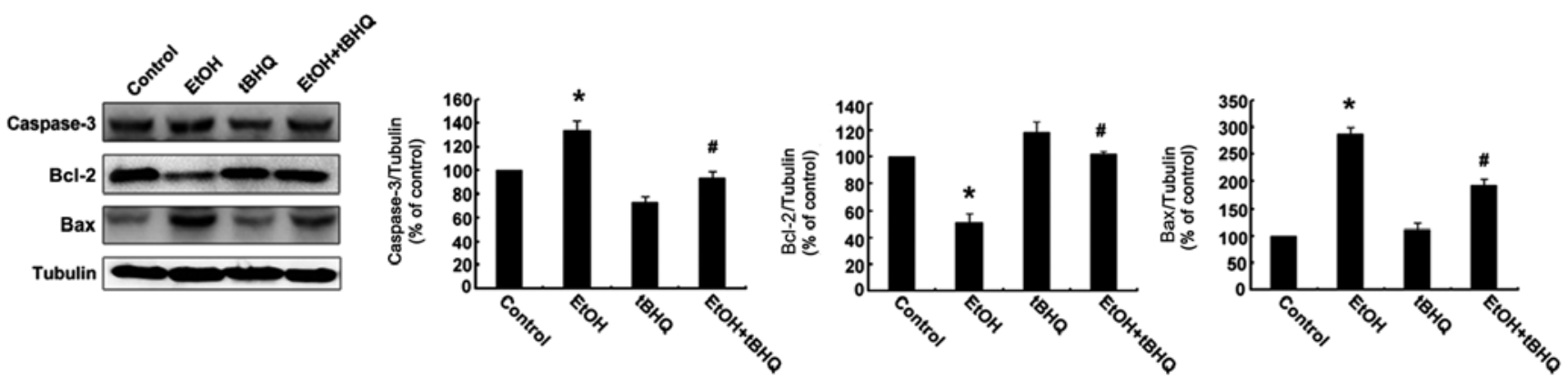

Figure 3. Representative western blots illustrating protein expression. Apoptosis was measured in the $\mathrm{H} 9 \mathrm{c} 2$ cells cultured in control medium (control), as well as those exposed to $200 \mathrm{mM}$ ethanol (EtOH) or $5 \mu \mathrm{M}$ tert-butylhydroquinone (tBHQ) (tBHQ) alone, or exposed to EtOH and pre-treated with $\mathrm{tBHQ}$ (EtOH + tBHQ). The data are expressed as a densitometric ratio. The values are the means $\pm \mathrm{SD} ; \mathrm{n}=3$ experiments, ${ }^{*} \mathrm{p}<0.05$ vs. control, ${ }^{*} \mathrm{p}<0.05 \mathrm{vs}$. EtOH.

exposure to ethanol at $200 \mathrm{mM}$ for $24 \mathrm{~h}$ significantly decreased the percentage of surviving cells. Thus, the concentration of $200 \mathrm{mM}$ ethanol was used as a standard concentration with which to induce apoptosis in the subsequent experiments. The results of MTT assay demonstrated no decrease in the viability of cells exposed to various concentrations of tBHQ $(0,0.625,1.25,2.5$, $5,10,20,50$ and $100 \mu \mathrm{M}$ ) for $48 \mathrm{~h}$ (Fig. 1B). Furthermore, the results revealed that pre-incubation of the $\mathrm{H} 9 \mathrm{c} 2$ cardiomyocytes with various concentrations of tBHQ $(0,0.625,1.25,2.5,5,10$, $20,50$ and $100 \mu \mathrm{M})$ enhanced cell viability which was decreased due to exposure to ethanol in a dose-dependent manner (Fig. 1C). Maximum viability was apparent at a concentration of $5 \mu \mathrm{M}$. However, higher concentrations (50 and $100 \mu \mathrm{M}$ ) of tBHQ did not cause any attenuation of the inhibitory effects of ethanol on cell viability. Therefore, we employed $5 \mu \mathrm{M}$ of $\mathrm{tBHQ}$ as a concentration for use in our subsequent experiments.

Treatment with $\mathrm{tBHQ}$ prevents the ethanol-induced apoptosis of $H 9 c 2$ cells. We performed a flow cytometric analysis and found that ethanol caused a substantial increase in the number of apoptotic cells, whereas pre-treatment with tBHQ significantly lowered the amount of apoptotic cells compared with the cells exposed to ethanol alone (Fig. 2). In addition, the results of western blot analysis revealed that the H9c2 cells exposed to ethanol manifested a marked increase in the expression of the apoptotic protein, caspase-3, and the pro-apoptotic protein, Bax, while a significant decrease in the expression of the anti-apoptotic protein, Bcl-2, was observed. However, the pretreatment with tBHQ markedly inhibited the ethanol-induced increase in caspase-3 and Bax expression, and enhanced Bcl-2 expression (Fig. 3).

Treatment with $t B H Q$ significantly prevents the ethanolinduced excessive production of ROS in H9c2 cells. To determine whether tBHQ can prevent the oxidative stress induced by ethanol in cardiomyocytes, a cDCFH-DA assay (Beyotime Biotechnology) was performed to measure ROS production, representing one of the key events in apoptotic cell death. We found that the exposure to ethanol at $200 \mathrm{mM}$ induced considerable ROS production, which was attenuated significantly by pre-treatment with BHQ (Fig. 4).

Treatment with $\mathrm{tBHQ}$ restores the expression of antioxidant proteins, including SOD, CAT and HO-1 in ethanol-exposed $H 9 c 2$ cells. Western blot analysis was performed to determine whether tBHQ affects the expression of Nrf2 downstream antioxidant proteins (SOD, HO-1, and CAT) in H9c2 cells exposed to ethanol. As illustrated in Fig. 5, the protein expression of 

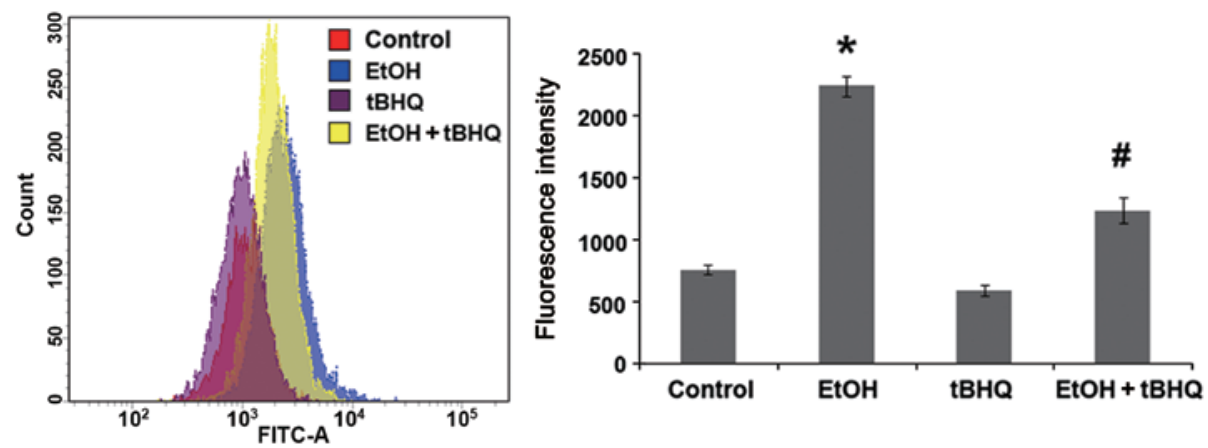

Figure 4. Pre-treatment with tert-butylhydroquinone (tBHQ) significantly diminishes reactive oxygen species (ROS) generation in ethanol (EtOH)-exposed $\mathrm{H} 9 \mathrm{c} 2$ cells. ROS generation was detected in $\mathrm{H} 9 \mathrm{c} 2$ cells cultured in control medium (control), exposed to $200 \mathrm{mM} \mathrm{EtOH}$ or $5 \mu \mathrm{M}$ tBHQ (tBHQ) alone, or exposed to $\mathrm{EtOH}$ and pre-treated with $\mathrm{tBHQ}(\mathrm{EtOH}+\mathrm{tBHQ})$. The data are shown as relative fluorescence intensity units and represent the means \pm SD of 3 separate experiments; ${ }^{*} \mathrm{p}<0.05$ vs. control, ${ }^{*} \mathrm{p}<0.05$ vs. EtOH.
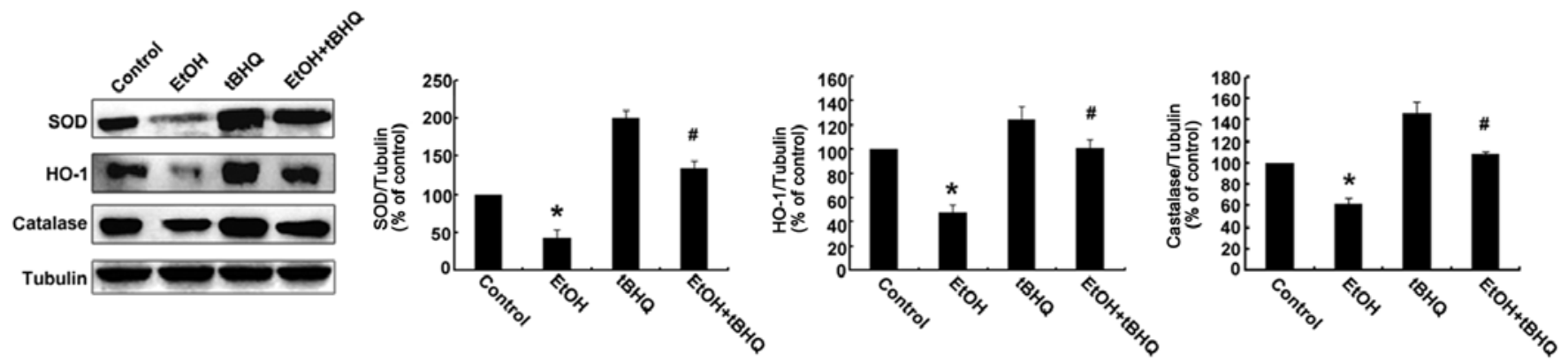

Figure 5. Tert-butylhydroquinone (tBHQ) prevents the ethanol (EtOH)-induced inhibition of antioxidant protein expression in H9c2 cells. Cell lysates were prepared from $\mathrm{H} 9 \mathrm{c} 2$ cells cultured in control medium (control), exposed to $200 \mathrm{mM}$ EtOH or tBHQ at $5 \mu \mathrm{M}$ without EtOH, or exposed to EtOH and pre-treated with $\mathrm{tBHQ}(\mathrm{EtOH}+\mathrm{tBHQ})$. The data are expressed as the means $\pm \mathrm{SD}$ of 3 separate experiments; ${ }^{*} \mathrm{p}<0.05 \mathrm{vs}$. control, ${ }^{\#} \mathrm{p}<0.05 \mathrm{vs}$. EtOH.
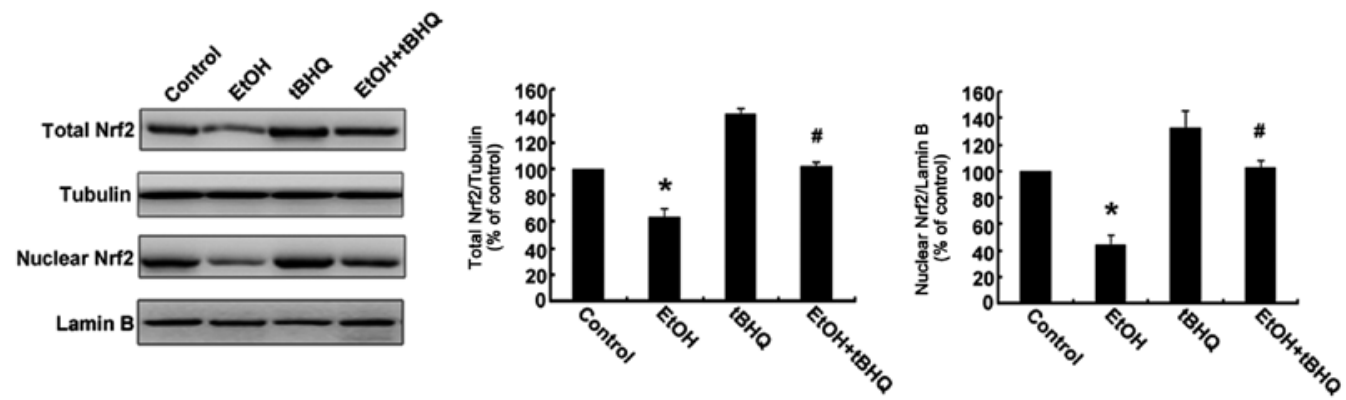

Figure 6. Pre-treatment with tert-butylhydroquinone (tBHQ) restores the total nuclear factor erythroid 2-related factor 2 (Nrf2) protein level and nuclear accumulation which are inhibited by ethanol (EtOH) in $\mathrm{H} 9 \mathrm{c} 2$ cells. Western blot analysis was performed to analyze the level of Nrf2 protein. Cell lysates were prepared from $\mathrm{H} 9 \mathrm{c} 2$ cells cultured in control medium (control), exposed to $200 \mathrm{mM}$ EtOH or $5 \mu \mathrm{M}$ tBHQ (tBHQ) alone, or exposed to EtOH and pre-treated with $\mathrm{tBHQ}(\mathrm{EtOH}+\mathrm{tBHQ})$. The data are expressed as fold change over control and represent the means $\pm \mathrm{SD}$ of 3 separate experiments; " $\mathrm{p}<0.05 \mathrm{vs.}$ control, ${ }^{\#} \mathrm{p}<0.05$ vs. EtOH.

SOD, HO-1 and CAT was decreased in the ethanol-exposed cells compared with that in the ethanol-untreated cells, whereas it was restored by tBHQ in the ethanol-exposed H9c2 cells.

Treatment with $t B H Q$ increases the protein expression and promotes the nuclear translocation of Nrf2 which is inhibited by exposure to ethanol in $\mathrm{H} 9 \mathrm{c} 2$ cells. As depicted in Figs. 6 and 7, ethanol inhibited not only Nrf2 protein expression, but also Nrf2 nuclear translocation, which may have made the cells more sensitive to ethanol-induced toxicity. tBHQ alone partially, but significantly increased the Nrf2 protein level in the H9c2 cells. Pre-treatment wit htBHQ restored the level of Nrf2 protein and promoted its nuclear accumulation in the H9c2 cells, which were inhibited by exposure to ethanol, which may have elicited the cytoprotective response, resulting in the increased resistance of the cells to the ethanol challenge. The above-mentioned results were confirmed by western blot analysis and immunofluorescence staining.

\section{Discussion}

Previous studies have demonstrated that apoptosis is the major factor responsible for ethanol-induced myocardial cell death, which is closely associated with ACM (1). For this reason, for 


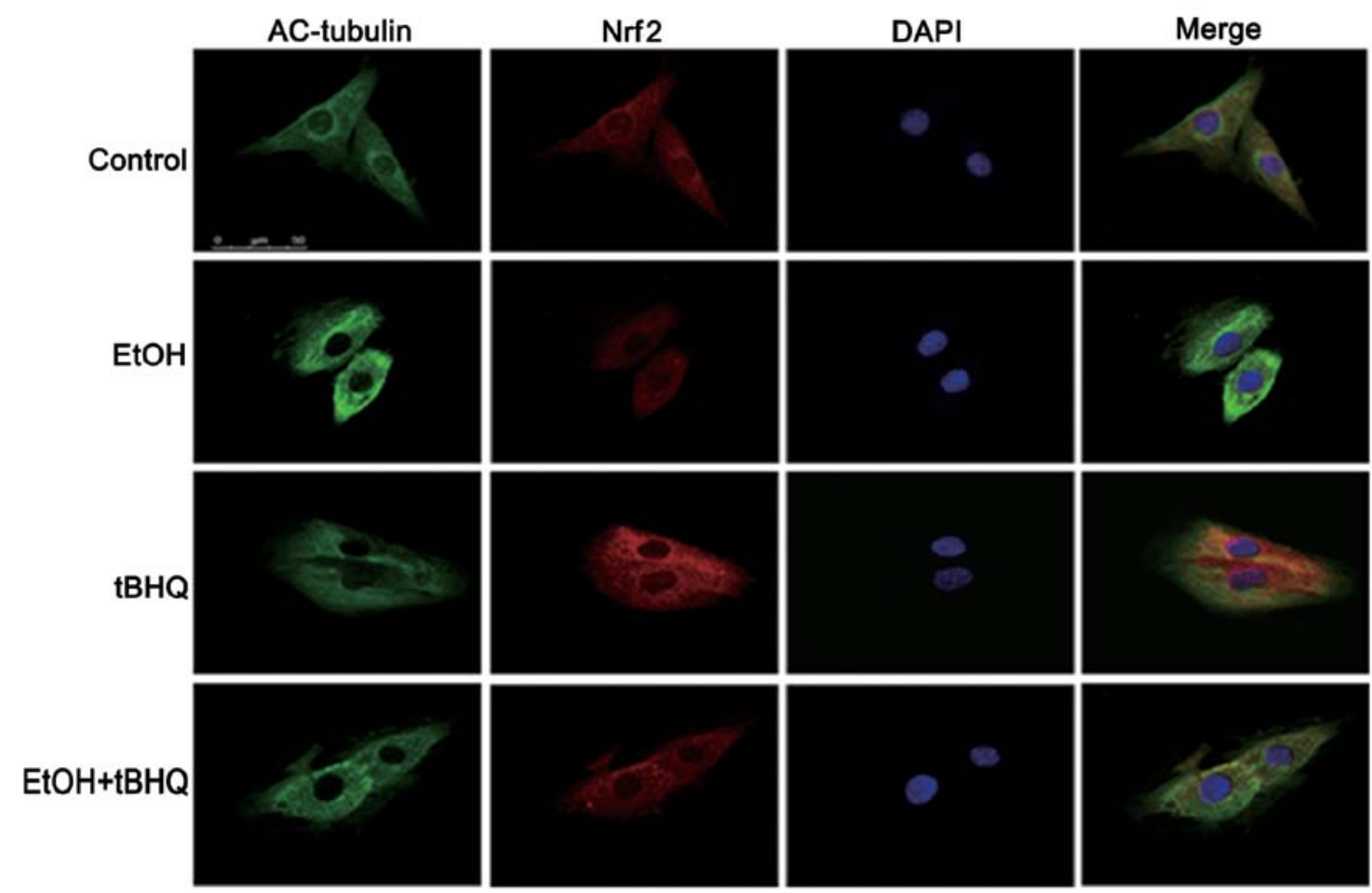

Figure 7. The immunofluorescence assay evidenced that tert-butylhydroquinone (tBHQ) promotes the nuclear translocation of nuclear factor erythroid 2-related factor 2 (Nrf2) in H9C2 cells. Nrf2 protein was visualized with a TRITC-labeled antibody, AC-tubulin was visualized with an FITC-labeled antibody, and the nuclear morphology was visualized with DAPI dye.

preventing ACM, it is crucial to find an effective anti-apoptotic agent. In this study, treatment with tBHQ significantly reduced the occurrence of ethanol-induced cardiomyocyte apoptosis and promoted cell survival, as confirmed by the results of MTT assay, flow cytometry and the expression of caspase-3. Simultaneously, treatment withy tBHQ significantly reduced the ethanol-induced generation of ROS (as shown in Fig. 4). Furthermore, treatment with tBHQ not only promoted the nuclear translocation of Nrf2 (as depicted in Fig. 7), but also increased Nrf2 expression which was decreased by the exposure of the H9c2 cells to ethanol, which in turn led to the enhancement of the levels of antioxidant proteins, including SOD, HO-1 and CAT. In addition, the results also revealed that tBHQ protected the H9c2 cells from ethanol-induced apoptosis by participating in the upregulation of $\mathrm{Bcl}-2$ expression and the downregulation of Bax expression. Taken together, these results provide substantial evidence that tBHQ can protect H9c2 cardiomyocytes against ethanol-induced oxidative stress and apoptosis, which may be associated with the activation of the Nrf2 antioxidant response pathway. To the best of our knowledge, this study is the first to demonstrate the cardioprotective effects of tBHQ on the apoptosis of H9c2 cardiomyocytes induced by ethanol.

Oxidative stress is well known as a major mechanism leading to apoptosis induced by ethanol (8-10). ROS are the major cause of cellular oxidative stress, which can both oxidize biomolecules and regulate the expression of genes related to apoptosis, and can serve as a signaling link between ethanol-induced oxidative stress and apoptosis, leading to cell apoptosis $(16,34)$. In the present study, we confirmed that the exposure of $\mathrm{H} 9 \mathrm{c} 2$ cells to $200 \mathrm{mM}$ ethanol increased ROS generation excessively (Fig. 4). In our experiments, $200 \mathrm{mM}$ ethanol was used as an inducing concentration according to the results of MTT assay and our pilot trial. It is a high-dose concentration which has been confirmed to effectively induce the ROS-mediated apoptosis of cardiomyocytes (34). The results from this study also demonstrated that ethanol markedly induced the apoptosis of $\mathrm{H} 9 \mathrm{c} 2$ cells, as indicated by the results of flow cytometric analysis, which revealed a significant increase in the apoptotic cell number in the ethanol-exposed H9c2 cells as compared to the controls (Fig. 2). In parallel, ethanol activated caspase- 3 and Bax, but inhibited Bcl-2, as shown in Fig. 3. These results further confirmed that the oxidative stress induced by ethanol played a crucial role in eliciting cardiomyocyte apoptosis. Thus, anti-oxidative stress processes may indeed be critically beneficial to prevent apoptosis and protect cardiac function.

tBHQ is a potent antioxidant compound which exerts protective effects on multiple cells and organs, including neuroprotective (35-37), hepatoprotective (38) and renal protective effects $(30,39)$. It has been shown that $\mathrm{tBHQ}$ diminishes apoptosis by reducing oxidative stress (37). More importantly, tBHQ inhibits ethanol-induced oxidative stress and the apoptosis of cranial neural crest cells (33). Through examination, we further evidenced that $\mathrm{BHQ}$ markedly inhibited the apoptosis of cardiomyocytes exposed to ethanol (as confirmed by MTT assay, Annexin V-FITC staining and the protein expression of caspase-3) accompanied by a decrease of ROS (as illustrated in Fig. 4). As a central regulator of oxidative stress, Nrf2 can effectively inhibit ROS generation and prevent apoptosis $(40,41)$. Following activation, Nrf2 can translocate to the nucleus to promote the expression of antioxidant enzymes to reduce 
ROS and prevent apoptosis (42). Moreover, other researchers have found that Nrf2 increases the levels of the anti-apoptotic proteins, Bcl-2 and Bcl-xL, which inhibits apoptosis (43). Nrf2 can be activated by a chemical inducer. tBHQ has long been known as an effective inducer of Nrf2 (36). Substantial evidence has indicated that activating the Nrf2 pathway by tBHQ can prevent apoptosis $(27,29)$. Independently of Nrf2 activation, other protective mechanisms of tBHQ are also involved in the induction of autophagy $(44,45)$. In addition, a recent study demonstrated that tBHQ activated Akt rather than Nrf2 to suppress apoptosis (46). In our study, pre-treatment with tBHQ significantly restored the level of Nrf2 protein (Fig. 6) and promoted nuclear translocation (as shown in Fig. 7) previously inhibited by ethanol exposure in $\mathrm{H} 9 \mathrm{c} 2$ cells, with an increase in the levels of the antioxidant proteins, SOD, HO-1 and CAT. All the findings mentioned above provide substantial evidence that tBHQ enhances the resistance against ethanol-induced cytotoxicity in H9c2 cells, and activates the Nrf2 cytoprotective response pathway, thus reducing apoptosis.

There are many studies demonstrating that the antiapoptotic Bcl-2 and pro-apoptotic Bax genes play a major role in maintaining the balance of cell death and survival, and the upregulation of the anti-apoptotic $\mathrm{Bcl}-2$ protein can antagonize the pro-apoptotic activities of Bax (47). Moreover, Niture and Jaiswal found that tBHQ antagonized Bcl-2, INrf2 (inhibitor of Nrf2) interaction, led to the release and stabilization of Bcl-2, increased Bcl-2, Bax heterodimers, and reduced the apoptosis of mouse Hepa-1 cells (48). Further examination indicated that pre-treatment with tBHQ destabilized Nrf2-Keapl/PGAM5 (phosphog1ycerate mutase 5)-Bcl-xL, increased the release of Bcl-xL and inhibited apoptosis (49). In the present study, we found that ethanol markedly downregulated Bcl-2 expression, while it upregulated Bax expression. Conversely, pre-treatment with $\mathrm{tBHQ}$ reversed these changes in Bax and $\mathrm{Bcl}-2$ protein expression in the $\mathrm{H} 9 \mathrm{c} 2$ cardiomyocytes exposed to ethanol, as confirmed by the resutls of western blot analysis. Consistently, pre-treatment with tBHQ markedly inhibited the ethanolinduced increase in the expression of caspase-3 in H9c2 cells.

In conclusion, these new experimental findings indicate that pre-treatment with tBHQ protects $\mathrm{H} 9 \mathrm{c} 2$ cardiomyocytes against ethanol-induced oxidative stress and apoptosis. Our results also suggest that the anti-apoptotic effects of tBHQ are at least partly mediated by the inhibition of ROS generation, the activation of Nrf2 signaling pathway, the reduction of caspase-3 expression and the modulation of $\mathrm{Bcl}-2$ and Bax expression. tBHQ may thus provide a valuable therapeutic intervention for the treatment of ACM.

\section{References}

1. Piano MR and Phillips SA: Alcoholic cardiomyopathy: pathophysiologic insights. Cardiovasc Toxicol 14: 291-308, 2014.

2. Capasso JM, Li P, Guideri G, Malhotra A, Cortese R and Anversa P: Myocardial mechanical, biochemical, and structural alterations induced by chronic ethanol ingestion in rats. Circ Res 71: 346-356, 1992.

3. Li SY, Li Q, Shen JJ, Dong F, Sigmon VK, Liu Y and Ren J: Attenuation of acetaldehyde-induced cell injury by overexpression of aldehyde dehydrogenase-2 (ALDH2) transgene in human cardiac myocytes: role of MAP kinase signaling. J Mol Cell Cardiol 40: 283-294, 2006.

4. Chen DB, Wang L and Wang PH: Insulin-like growth factor I retards apoptotic signaling induced by ethanol in cardiomyocytes. Life Sci 67: 1683-1693, 2000.
5. Tan Y, Li X, Prabhu SD, Brittian KR, Chen Q, Yin X, McClain CJ, Zhou Z and Cai L: Angiotensin II plays a critical role in alcoholinduced cardiac nitrative damage, cell death, remodeling, and cardiomyopathy in a protein kinase $\mathrm{C} /$ nicotinamide adenine dinucleotide phosphate oxidase-dependent manner. J Am Coll Cardiol 59: 1477-1486, 2012.

6. Fernández-Solà J, Fatjó F, Sacanella E, Estruch R, Bosch X, Urbano-Márquez A and Nicolás JM: Evidence of apoptosis in alcoholic cardiomyopathy. Hum Pathol 37: 1100-1110, 2006.

7. Fernández-Solà J, Lluis M, Sacanella E, Estruch R, Antúnez E and Urbano-Márquez A: Increased myostatin activity and decreased myocyte proliferation in chronic alcoholic cardiomyopathy. Alcohol Clin Exp Res 35: 1220-1229, 2011.

8. Kannan M, Wang L and Kang YJ: Myocardial oxidative stress and toxicity induced by acute ethanol exposure in mice. Exp Biol Med (Maywood) 229: 553-559, 2004.

9. Guan Z, Lui CY, Morkin E and Bahl JJ: Oxidative stress and apoptosis in cardiomyocyte induced by high-dose alcohol. J Cardiovasc Pharmacol 44: 696-702, 2004.

10. Jing L, Jin CM, Li SS, Zhang FM, Yuan L, Li WM, Sang Y, Li S and Zhou LJ: Chronic alcohol intake-induced oxidative stress and apoptosis: role of CYP2E1 and calpain-1 in alcoholic cardiomyopathy. Mol Cell Biochem 359: 283-292, 2012.

11. Umoh NA, Walker RK, Al-Rubaiee M, Jeffress MA and Haddad GE: Acute alcohol modulates cardiac function as PI3K/Akt regulates oxidative stress. Alcohol Clin Exp Res 38: 1847-1864, 2014

12. Ho E, Karimi Galougahi K, Liu CC, Bhindi R and Figtree GA: Biological markers of oxidative stress: applications to cardiovascular research and practice. Redox Biol 1: 483-491, 2013.

13. Lucas DL, Brown RA, Wassef M and Giles TD: Alcohol and the cardiovascular system: research challenges and opportunities. J Am Coll Cardiol 45: 1916-1924, 2005.

14. Zhang RH, Gao JY, Guo HT, Scott GI, Eason AR, Wang XM and Ren J: Inhibition of CYP2E1 attenuates chronic alcohol intake-induced myocardial contractile dysfunction and apoptosis. Biochim Biophys Acta 1832: 128-141, 2013.

15. Kannan $\mathrm{K}$ and Jain SK: Oxidative stress and apoptosis. Pathophysiology 7: 153-163, 2000.

16. Zu L, Zheng X, Wang B, Parajuli N, Steenbergen C, Becker LC and Cai ZP: Ischemic preconditioning attenuates mitochondrial localization of PTEN induced by ischemia-reperfusion. Am J Physiol Heart Circ Physiol 300: H2177-H2186, 2011.

17. Kino M: Chronic effects of ethanol under partial inhibition of catalase activity in the rat heart: light and electron microscopic observations. J Mol Cell Cardiol 13: 5-21, 1981.

18. Jaiswal AK: Nrf2 signaling in coordinated activation of antioxidant gene expression. Free Radic Biol Med 36: 1199-1207, 2004.

19. Li J, Ichikawa T, Villacorta L, Janicki JS, Brower GL, Yamamoto $\mathrm{M}$ and Cui T: Nrf2 protects against maladaptive cardiac responses to hemodynamic stress. Arterioscler Thromb Vasc Biol 29: 1843-1850, 2009.

20. Calvert JW, Elston M, Nicholson CK, Gundewar S, Jha S, Elrod JW, Ramachandran A and Lefer DJ: Genetic and pharmacologic hydrogen sulfide therapy attenuates ischemia-induced heart failure in mice. Circulation 122: 11-19, 2010.

21. Li J, Zhang C, Xing Y, Janicki JS, Yamamoto M, Wang XL, Tang DQ and Cui T: Up-regulation of p27(kip1) contributes to Nrf2-mediated protection against angiotensin II-induced cardiac hypertrophy. Cardiovasc Res 90: 315-324, 2011.

22. Li S, Wang W, Niu T, Wang H, Li B, Shao L, Lai Y, Li H, Janicki JS, Wang XL, et al: Nrf2 deficiency exaggerates doxorubicin-induced cardiotoxicity and cardiac dysfunction. Oxid Med Cell Longev 2014: 748524, 2014.

23. Li J, Ichikawa T, Janicki JS and Cui T: Targeting the Nrf2 pathway against cardiovascular disease. Expert Opin Ther Targets 13: 785-794, 2009.

24. Walker RK, Cousins VM, Umoh NA, Jeffress MA, Taghipour D, Al-Rubaiee $M$ and Haddad GE: The good, the bad, and the ugly with alcohol use and abuse on the heart. Alcohol Clin Exp Res 37: 1253-1260, 2013.

25. Dong J, Yan D and Chen SY: Stabilization of Nrf2 protein by D3T provides protection against ethanol-induced apoptosis in PC12 cells. PLoS One 6: e16845, 2011.

26. Chen X, Liu J and Chen SY: Sulforaphane protects against ethanol-induced oxidative stress and apoptosis in neural crest cells by the induction of Nrf2-mediated antioxidant response. $\mathrm{Br}$ J Pharmacol 169: 437-448, 2013. 
27. Li J, Johnson D, Calkins M, Wright L, Svendsen C and Johnson J: Stabilization of Nrf2 by tBHQ confers protection against oxidative stress-induced cell death in human neural stem cells. Toxicol Sci 83: 313-328, 2005.

28. Kaspar JW and Jaiswal AK: An autoregulatory loop between Nrf2 and Cul3-Rbx1 controls their cellular abundance. J Biol Chem 285: 21349-21358, 2010

29. Wu J, Cheng M, Liu Q, Yang J, Wu S, Lu X, Jin C, Ma H and Cai Y: Protective role of tert-butylhydroquinone against sodium fluoride-induced oxidative stress and apoptosis in PC12 cells. Cell Mol Neurobiol 35: 1017-1025, 2015.

30. Li H, Zhang L, Wang F, Shi Y, Ren Y, Liu Q, Cao Y and Duan H: Attenuation of glomerular injury in diabetic mice with tert-butylhydroquinone through nuclear factor erythroid 2-related factor 2-dependent antioxidant gene activation. Am J Nephrol 33: 289-297, 2011

31. Wang Z, Ji C, Wu L, Qiu J, Li Q, Shao Z and Chen G: Tert-butylhydroquinone alleviates early brain injury and cognitive dysfunction after experimental subarachnoid hemorrhage: role of Keap1/Nrf2/ARE pathway. PLoS One 9: e97685, 2014.

32. Gharavi N, Haggarty S and El-Kadi AO: Chemoprotective and carcinogenic effects of tert-butylhydroquinone and its metabolites. Curr Drug Metab 8: 1-7, 2007.

33. Yan D, Dong J, Sulik KK and Chen SY: Induction of the Nrf2-driven antioxidant response by tert-butylhydroquinone prevents ethanol-induced apoptosis in cranial neural crest cells. Biochem Pharmacol 80: 144-149, 2010.

34. Wang Y, Zhao J, Yang W, Bi Y, Chi J, Tian J and Li W: High-dose alcohol induces reactive oxygen species-mediated apoptosis via $\mathrm{PKC}-\beta / \mathrm{p} 66 \mathrm{Shc}$ in mouse primary cardiomyocytes. Biochem Biophys Res Commun 456: 656-661, 2015.

35. Jin W, Ni H, Dai Y, Wang H, Lu T, Wu J, Jiang J and Liang W: Effects of tert-butylhydroquinone on intestinal inflammatory response and apoptosis following traumatic brain injury in mice. Mediators Inflamm 2010: 502564, 2010.

36. Kraft AD, Johnson DA and Johnson JA: Nuclear factor E2-related factor 2-dependent antioxidant response element activation by tert-butylhydroquinone and sulforaphane occurring preferentially in astrocytes conditions neurons against oxidative insult. $\mathrm{J}$ Neurosci 24: 1101-1112, 2004.

37. Sun J, Ren X and Simpkins JW: Sequential upregulation of superoxide dismutase 2 and heme oxygenase 1 by tert-butylhydroquinone protects mitochondria during oxidative stress. Mol Pharmacol 88: 437-449, 2015.

38. Duan X, Liu D, Xing X, Li J, Zhao S, Nie H, Zhang Y, Sun G and Li B: Tert-butylhydroquinone as a phenolic activator of Nrf2 antagonizes arsenic-induced oxidative cytotoxicity but promotes arsenic methylation and detoxication in human hepatocyte cell line. Biol Trace Elem Res 160: 294-302, 2014.
39. Wang C, Li C, Peng H, Ye Z, Zhang J, Liu X and Lou T: Activation of the Nrf2-ARE pathway attenuates hyperglycemia-mediated injuries in mouse podocytes. Cell Physiol Biochem 34: 891-902, 2014.

40. He X, Kan H, Cai L and Ma Q: Nrf2 is critical in defense against high glucose-induced oxidative damage in cardiomyocytes. J Mol Cell Cardiol 46: 47-58, 2009.

41. Chen X, Liu J and Chen SY: Over-expression of Nrf2 diminishes ethanol-induced oxidative stress and apoptosis in neural crest cells by inducing an antioxidant response. Reprod Toxicol 42: 102-109, 2013.

42. Huang XS, Chen HP, Yu HH, Yan YF, Liao ZP and Huang QR: Nrf2-dependent upregulation of antioxidative enzymes: a novel pathway for hypoxic preconditioning-mediated delayed cardioprotection. Mol Cell Biochem 385: 33-41, 2014.

43. Calvert JW, Jha S, Gundewar S, Elrod JW, Ramachandran A, Pattillo CB, Kevil CG and Lefer DJ: Hydrogen sulfide mediates cardioprotection through Nrf2 signaling. Circ Res 105: 365-374, 2009.

44. Li S, Li J, Shen C, Zhang X, Sun S, Cho M, Sun C and Song Z: Tert-butylhydroquinone (tBHQ) protects hepatocytes against lipotoxicity via inducing autophagy independently of Nrf2 activation. Biochim Biophys Acta 1841: 22-33, 2014.

45. Li T, Sun KJ, Wang HD, Zhou ML, Ding K, Lu XY, Wei WT, Wang CX and Zhou XM: Tert-butylhydroquinone ameliorates early brain injury after experimental subarachnoid hemorrhage in mice by enhancing Nrf2-independent autophagy. Neurochem Res 40: 1829-1838, 2015.

46. Zhang Y, Liu FF, Bi X, Wang S, Wu X and Jiang F: The antioxidant compound tert-butylhydroquinone activates Akt in myocardium, suppresses apoptosis and ameliorates pressure overload-induced cardiac dysfunction. Sci Rep 5: 13005, 2015.

47. Reed JC: Double identity for proteins of the Bcl-2 family. Nature 387: 773-776, 1997.

48. Niture SK and Jaiswal AK: INrf2 (Keap1) targets Bcl-2 degradation and controls cellular apoptosis. Cell Death Differ 18: 439-451, 2011.

49. Niture SK and Jaiswal AK: Inhibitor of Nrf2 (INrf2 or Keap1) protein degrades $\mathrm{Bcl}-\mathrm{xL}$ via phosphoglycerate mutase 5 and controls cellular apoptosis. J Biol Chem 286: 44542-44556, 2011. 